\title{
Prevalence of Malnutrition amongst Tribal School Children of Sabarkantha District, Gujarat, India
}

\author{
Preeti H. Dave $^{1 *}$, J.J. Mistry ${ }^{2}$, M.K. Chaudhary ${ }^{3}$ and Shamal S. Patel ${ }^{4}$ \\ ${ }^{1}$ Food \& Nutrition, ${ }^{2,4}$ Extension Education, ${ }^{3}$ Agriculture Statistics, Sardarkrushinagar \\ Dantiwada Agricultural University, S.K.Nagar, Banaskantha, Gujarat, India \\ *Corresponding author:
}

Keywords

Malnutrition,

Tribal children,

Anthropometric

measurements

Article Info

Accepted:

18 February 2019

Available Online:

10 March 2019

\section{A B S T R A C T}

Malnutrition is largely prevalent in tribal population in India. In the year 2006, the Ministry of Panchayati Raj considered Sabarkantha as one of the country's 250 most backward districts (out of a total of 640). Six districts of Gujarat are receiving funds from the Backward Regions Grant Fund Programme (BRGF) and Sabarkantha is one of them. Considering this background in mind, the present study was carried out to assess prevalence of malnutrition amongst tribal children of Sabarkantha district. Two tribal taluka viz. Khedbrahma and Poshina were purposively selected for the study. Three villages from both the selected taluka and total 120 tribal school going children (60 girls and 60 boys) were selected for the study. To assess the prevalence of malnutrition anthropometric parameters of the tribal children were studied. Statistical analysis was carried out to calculate frequency, per cent, mean, standard deviation and correlation. From the present study it was observed that mean BMI for age of the tribal children was found lower as compared to ICMR standards. As per Waterlow's classification, stunting, wasting and stunting and wasting was observed and it was found prevalent among tribal children. It was observed that the income of the family showed significant positive correlation with the BMI of the tribal children.

\section{Introduction}

Nutrition and health were the most important contributory factors for human resource development in the country (Amirthaveni and Barikor, 2001). But still undernourishment continued to be a major public health issue among children in developing countries like India. Most of the tribal people of India have their own geographically isolated life style. Tribes are found to be self sufficient people who largely depend on their land for livelihood and not integrated into the national society (Anonymous, 2004).

Tribal seems to be most exploited and ignored people and hence are more vulnerable to malnutrition, disease and disorders, morbidity and mortality. Their despair is due to illiteracy, poverty, unawareness wide spread diseases, hostile environment, poor sanitation, lack of safe drinking water and blind beliefs 
etc. (Balgir, 2011) Due to these factors, tribal children are especially vulnerable towards malnutrition.

National Nutrition Monitoring Bureau carried out a survey on diet and nutritional status of tribal population in the year 2009 and reported that the overall prevalence of thinness among 5-9 year children was about $37 \%$, with $10 \%$ having severe thinness and $27 \%$ having moderate thinness. The overall prevalence of thinness was highest in the State of Maharashtra (about 55\%) followed by $40-46 \%$ in the States of Karnataka, Gujarat \& Tamil Nadu, 25-35\% in Andhra Pradesh, Kerala, Orissa and West Bengal, with lowest of $23.3 \%$ in Madhya Pradesh. In the year 2006, the Ministry of Panchayati Raj considered Sabarkantha as one of the country's 250 most backward districts (out of a total of 640). Six districts of Gujarat are receiving funds from the Backward Regions Grant Fund Programme (BRGF) and Sabarkantha is one of them (Anonymous, 2009). Considering this background in mind, the present study was carried out to assess the nutritional status of tribal children of Sabarkantha and to check prevalence of malnutrition amongst tribal children.

\section{Materials and Methods}

\section{Locale of the study and sample selection}

The present study was conducted in Sabarkantha district of Gujarat. Two tribal taluka viz. Khedbrahma and Poshina were purposively selected for the study. Three villages from both the selected taluka were selected randomly. Total six villages were selected for the study. Multistage random sampling method was used. One primary school from each village was randomly selected. From each class of $4^{\text {th }}$ and $5^{\text {th }}$ standard five boys and five girls were selected randomly. Thus, from each primary school ten boys and ten girls were randomly selected.
Thus, sixty girls and sixty boys were selected for the present study. Total 120 tribal school going children were selected for the present study. To assess the prevalence of malnutrition anthropometric parameters of the tribal children were studied.

\section{Anthropometric Measurements}

Weight: An electronic weighing scale was used to measure the weight in kilograms. The scale was calibrated. Zero error was checked, children were without shoes and light clothing. The weighing machine was placed on a firm and flat ground.

Height: Height was measured by using stadiometer. Standing height was measured (to $0.5 \mathrm{~cm}$ ) without shoes, the child standing erect and looking straight.

Body mass index: BMI was calculated using anthropometric measurement (weight and height) of the tribal children and calculated by the formula given below:

$\mathrm{BMI}=\quad \frac{\text { Weight }(\mathrm{kg})}{\text { Height }(\mathrm{m})^{2}}$

Assessment of nutritional status was done by anthropometry using standard methods as per WHO growth standards 2007 of BMI for age. The classification of children in different grades of nutritional status was also done with the help of WHO growth standards 2007 (Anonymous, 2007). For assessing the nutritional status of tribal children, Waterlow classification was used (Waterlow, 1972). Using World Health Organization (WHO) standards, nutritional indices i.e. BMI for age was calculated.

\section{Statistical Analysis}

Using SPSS windows version 19.0, statistical analysis was carried out to calculate frequency, per cent, mean, standard deviation and correlation. 


\section{Background information}

A structured interview schedule was used to assess the socio economic status of the families of school going children (Aggarwal et al., 2005).

\section{Results and Discussion}

Table 1 shows the background information of the families of the tribal children. It was found that 99.2 per cent tribal children were Hindu. Most of the tribal children were living in medium size (4-8 members) families $(53.30 \%)$ followed by large (more than 8 members) families $(38.30 \%)$. Majority $(60.80 \%)$ of the families had five or more than five children. More than half of the families $(56.70 \%)$, were residing in kachcha house. Father's education of the tribal children was found low and 40.8 $\%$ of them were illiterate while total 52.50 percent were educated upto higher secondary only. Most of the $(73.30 \%)$ families of the tribal children were engaged in farming and animal husbandry. Large numbers of families $(63.30 \%)$ were fall under low income (yearly income upto Rs. 30,000) group and medium income (Rs. 30,000 to 60,000) group (34.20\%). Similar results were also found by Dave and Mistry (2017) who studied nutritional and health status of tribal farm women of Sabarkantha and reported about their poor socio-economic background i.e. low income, large family size, more number of children and living in kachcha houses. The problems of low standard of living, hunger, starvation, malnutrition, agricultural illiteracy, disease, poor sanitary and housing facilities are common to tribal people in comparison to the non-tribal [Vasudevachary, 2006].

Anthropometric measurements are the most common tool used to assess the nutritional status of a population and to monitor growth in children (Gorstein et al., 1994). According to WHO (1995), anthropometry provides an indication of risks as well as that of socioeconomic development. Anthropometry is widely used, easy and low cost method popularly used for assessment health and nutritional status of children. It can be used to verify the existence of a nutritional problem in a population and to assess the magnitude of malnutrition (Bisai, 2010). In the present study anthropometric parameters i.e. height, weight and BMI are used to assess malnutrition amongst tribal children. Table 2 shows classification of nutritional status of children according to Waterlow's classification. Waterlow's classification is very commonly used for the anthropometric studies and same is adopted for the present study. Data presented in the Table 2, shows that only 18.33 per cent children studying in $4^{\text {th }}$ standard and 36.66 per cent children studying in $5^{\text {th }}$ standard were found having normal nutritional status. Both stunting and wasting was observed in both the groups. It was also observed that wasting was more prevalent than stunting amongst tribal children.

UNICEF reports that stunting, or low height for age, is caused by long-term insufficient nutrient intake and frequent infections. Stunting generally occurs before age two, and effects are largely irreversible. These include delayed motor development, impaired cognitive function and poor school performance.

Nearly one third of children under five in the developing world are stunted. WHO reports that Low weight-for-height is called Wasting or thinness and it indicates in most cases a recent and severe process of weight loss, which is often associated with acute starvation and/or severe disease. However, wasting may also be the result of a chronic unfavourable condition.

Dave et al., (2016), conducted a study amongst tribal children of Sabarkantha and 
found that both the groups (girls and boys) showed almost similar values for mean height and weight. The data very clearly shows that both girls and boys were found having considerably lower mean values for height and weight as compared to the ICMR standards.

This indicated poor nutritional status and prevalence of malnutrition amongst the tribal children of both the gender. It was observed that there was no considerable difference in malnutrition amongst the girls and boys. More than half of the children were suffering from varying degree of malnutrition especially marginal and moderate malnutrition.

Laxmaiah et al., (2007) conducted a similar study in the tribal areas of Khammam District of Andhra Pradesh found that $65.4 \%$ children between 1-5 years were underweight. In a study conducted on tribal children of Chikhli taluka of Gujarat, according to WHO standards (2007), a high prevalence of under nutrition was observed among children below 3 years. Out of the total children, investigated 51.90 per cent were moderate to severely underweight, 54.70 percent were stunted and 27.10 were wasted (Seksaria and Sheth, 2013).

The indices of nutritional status (BMI for age) is expressed in standard deviation units ( $\mathrm{z}$ scores) from the reference median as recommended by the WHO.

Children with more than two standard deviations below the reference median on any of the indices were considered to be undernourished and the children who fell more than three standard deviations below the reference median were considered to be severely undernourished. Figure 1 and 2 shows WHO growth charts of BMI for age for girls and boys respectively. Both figures clearly indicate lower BMI for age amongst tribal girls and boys. It also shows poor nutritional status and prevalence of malnutrition amongst tribal children (Anonymous, 1986). Table 3 depicts the data regarding anthropometric measurements of the tribal children. Both tribal girls and boys showed almost similar values for mean BMI. The data very clearly show that both girls and boys were found having lower mean value for BMI as compared to standard.

This indicates poor nutritional status and prevalence of malnutrition amongst the tribal children of both the gender. Similar results were also observed in many other research studies carried out on tribal children in different parts of country. Das and Bose (2011) also reported similar findings and prevalence of stunting $(26.30 \%)$ and wasting $(12.70 \%)$ among the Santal tribal children of Midnapore in West Bengal.

In another study, malnutrition was observed more in male $(60.6 \%)$ than in female $(30.4 \%)$ tribal school children belonging to Satpura mountain ranges North West Maharhastra (Nagtilak and Motta, 2014). Grade I (mild), II (moderate) and II (severe) malnutrition among tribal children was observed in Munching put village, Paderu division, Visakhapatnam District (Sreedhar et al., 2016), amongst the tribal children of Thane, Nandurbar and Godchiroli districts of Maharashtra (Sonowal, 2010) and Kamar tribal children in Chhattisgarh (Mitra et al., 2007).

Table 4 represents relationship between income of the family and anthropological parameters of the tribal children. It was observed that the income of the family has showed significant positive correlation with the BMI of the tribal children.

This might be due to the reason that as the income of the family increases, their expenditure on food and availability of food increases. 
Table.1 Background information of the tribal children and their family

\begin{tabular}{|c|c|c|c|c|}
\hline & & & & $=120)$ \\
\hline Sr. No. & & ocial Attributes & Frequency & Per cent \\
\hline 1 & Religion & Hindu & 119 & 99.20 \\
\hline & & Muslim & 01 & 0.80 \\
\hline 2 & Type of family & Joint family & 58 & 48.30 \\
\hline & & Nuclear family & 62 & 51.70 \\
\hline 3 & Size of family & Small family (1-4 members) & 10 & 08.30 \\
\hline & & Medium family (4-8 members) & 64 & 53.30 \\
\hline & & Large family (> 8 members) & 46 & 38.30 \\
\hline 4 & No. of children in & 1 & 02 & 01.70 \\
\hline & family & 2 & 11 & 09.20 \\
\hline & & 3 & 22 & 18.30 \\
\hline & & 4 & 12 & 10.00 \\
\hline & & 5 & 14 & 11.70 \\
\hline & & 6 & 19 & 15.80 \\
\hline & & $>6$ & 40 & 33.30 \\
\hline 5 & Type of house & Kachcha house & 68 & 56.70 \\
\hline & & Pakka house & 52 & 43.30 \\
\hline 6 & Father's Education & Illiterate & 49 & 40.80 \\
\hline & & Primary Education & 18 & 15.00 \\
\hline & & Secondary Education & 25 & 20.80 \\
\hline & & Higher Secondary & 20 & 16.70 \\
\hline & & Under graduate & 7 & 5.80 \\
\hline & & Post Graduates & 1 & 1.20 \\
\hline 7 & Family Occupation & Farming & 14 & 11.70 \\
\hline & & Farming+ animal Husbandry & 88 & 73.30 \\
\hline & & Farming+ Farm laborer & 5 & 4.20 \\
\hline & & Framing + Business & 2 & 1.70 \\
\hline & & Farming + Services & 11 & 9.20 \\
\hline & & Only service & 14 & 11.70 \\
\hline 8 & & Low (Up to Rs. 30,000) & 76 & 63.30 \\
\hline & Family Income & Medium $(30,000$ to 60,000$)$ & 41 & 34.20 \\
\hline & (Yearly) & High $(>60,000)$ & 3 & 2.50 \\
\hline
\end{tabular}

Table.2 Distribution of the tribal children according to Waterlow's classification for nutritional grades

\begin{tabular}{|c|c|c|c|c|c|c|c|}
\hline & & & & & & $(\mathbf{n}=120)$ & \\
\hline \multirow[t]{2}{*}{ Sr. No. } & \multirow[t]{2}{*}{ Nutritional Grade } & \multicolumn{2}{|c|}{ Girls (60) } & \multicolumn{2}{|c|}{ Boys (60) } & \multicolumn{2}{|c|}{ Total } \\
\hline & & Frequency & Per cent & Frequency & Per cent & Frequency & Per cent \\
\hline & \multicolumn{7}{|c|}{ Tribal children from $4^{\text {th }}$ standards } \\
\hline 1 & Normal & 07.00 & 23.30 & 04.00 & 13.33 & 11.00 & 18.33 \\
\hline 2 & Stunted & 04.00 & 13.33 & 06.00 & 20.00 & 10.00 & 16.66 \\
\hline 3 & Wasted & 15.00 & 50.00 & 14.00 & 46.70 & 29.00 & 48.33 \\
\hline \multirow[t]{2}{*}{4} & Wasted and Stunted & 04.00 & 13.3 & 06.00 & 20.00 & 10.00 & 16.66 \\
\hline & \multicolumn{7}{|c|}{ Tribal children form $5^{\text {th }}$ standard } \\
\hline 1 & Normal & 11.00 & 36.70 & 11.00 & 36.70 & 22.00 & 36.66 \\
\hline 2 & Stunted & 04.00 & 13.30 & 01.00 & 03.30 & 05.00 & 08.33 \\
\hline 3 & Wasted & 11.00 & 50.00 & 17.00 & 56.70 & 28.00 & 46.66 \\
\hline 4 & Wasted and Stunted & 04.00 & 13.30 & 01.00 & 03.30 & 05.00 & 08.33 \\
\hline
\end{tabular}


Table.3 Distribution of the tribal children according to their BMI

\begin{tabular}{|c|c|c|c|}
\hline Sr. No. & BMI of the children & Girls (60) & Bovs (60) \\
\hline \multirow[t]{4}{*}{1.} & BMI for Age (Std. $\left.4^{\text {th }}\right)$ & & \\
\hline & BMI & $13.86+1.10$ & $13.87+1.12$ \\
\hline & ICMR Standard & 16.30 & 16.20 \\
\hline & Difference & -2.44 & -2.33 \\
\hline \multirow[t]{4}{*}{2.} & BMI for Age (Std. $\left.5^{\text {th }}\right)$ & & \\
\hline & BMI & $14.32+1.74$ & $14.14+0.61$ \\
\hline & ICMR Standard & 16.90 & $16 . \overline{60}$ \\
\hline & Difference & -2.58 & -2.46 \\
\hline
\end{tabular}

Table.4 Relationship between income and anthropological parameters of the tribal children

\begin{tabular}{|c|c|c|c|}
\hline No. & Independent Variables & Respondents (Std $\left.4^{\text {th }}\right)$ & Respondents (Std $5^{\text {th }}$ ) \\
\hline & & Income of the family & Income of the family \\
\hline 1 & Height & $-0.117^{\mathrm{NS}}$ & $0.018^{\mathrm{NS}}$ \\
\hline 2 & Weight & $0.152^{\mathrm{NS}}$ & $0.360^{* *}$ \\
\hline 3 & BMI & $0.492^{* *}$ & $0.453^{* *}$ \\
\hline
\end{tabular}

Fig.1 WHO growth chart showing BMI for age for girls

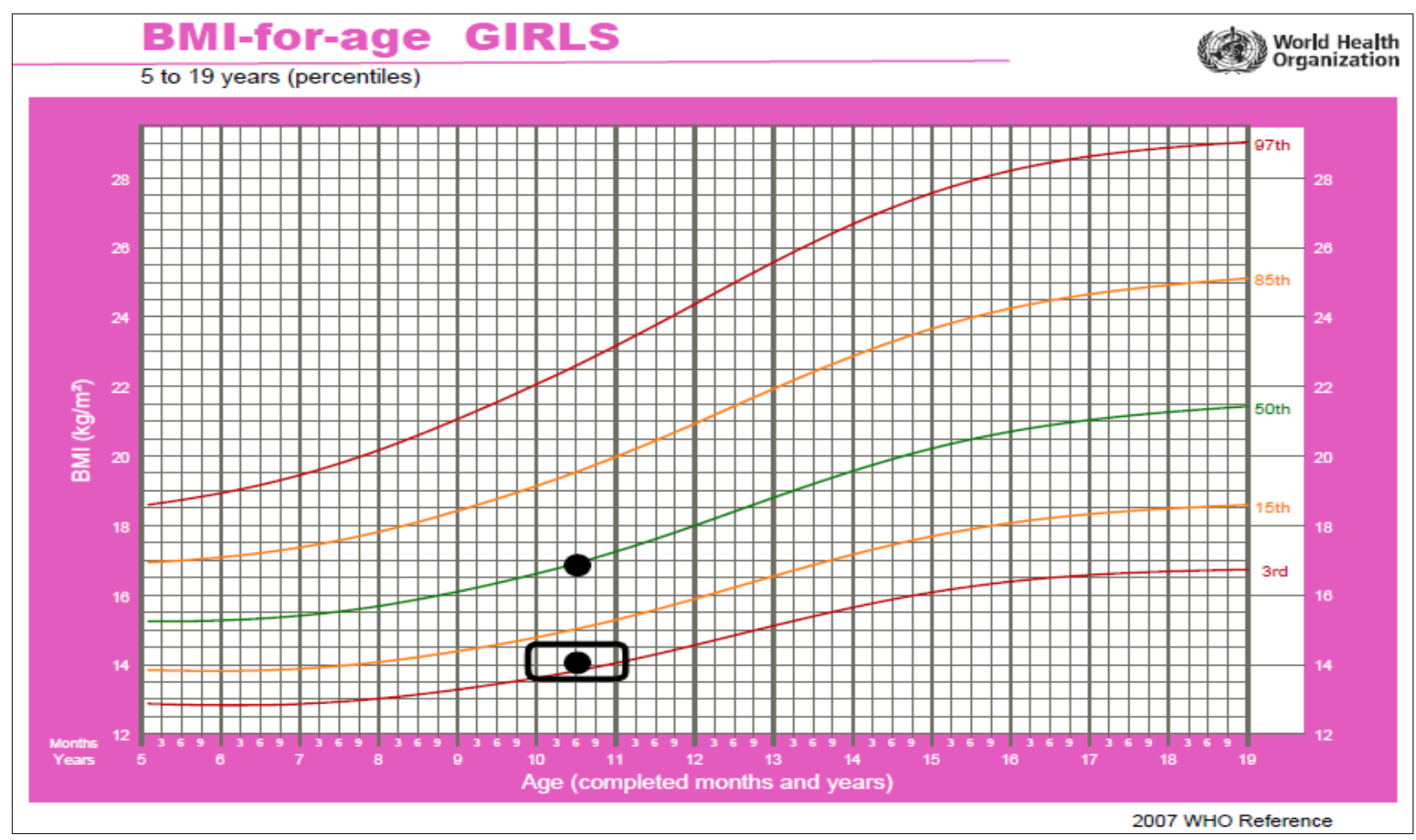


Fig.2 WHO growth chart showing BMI for age for boys

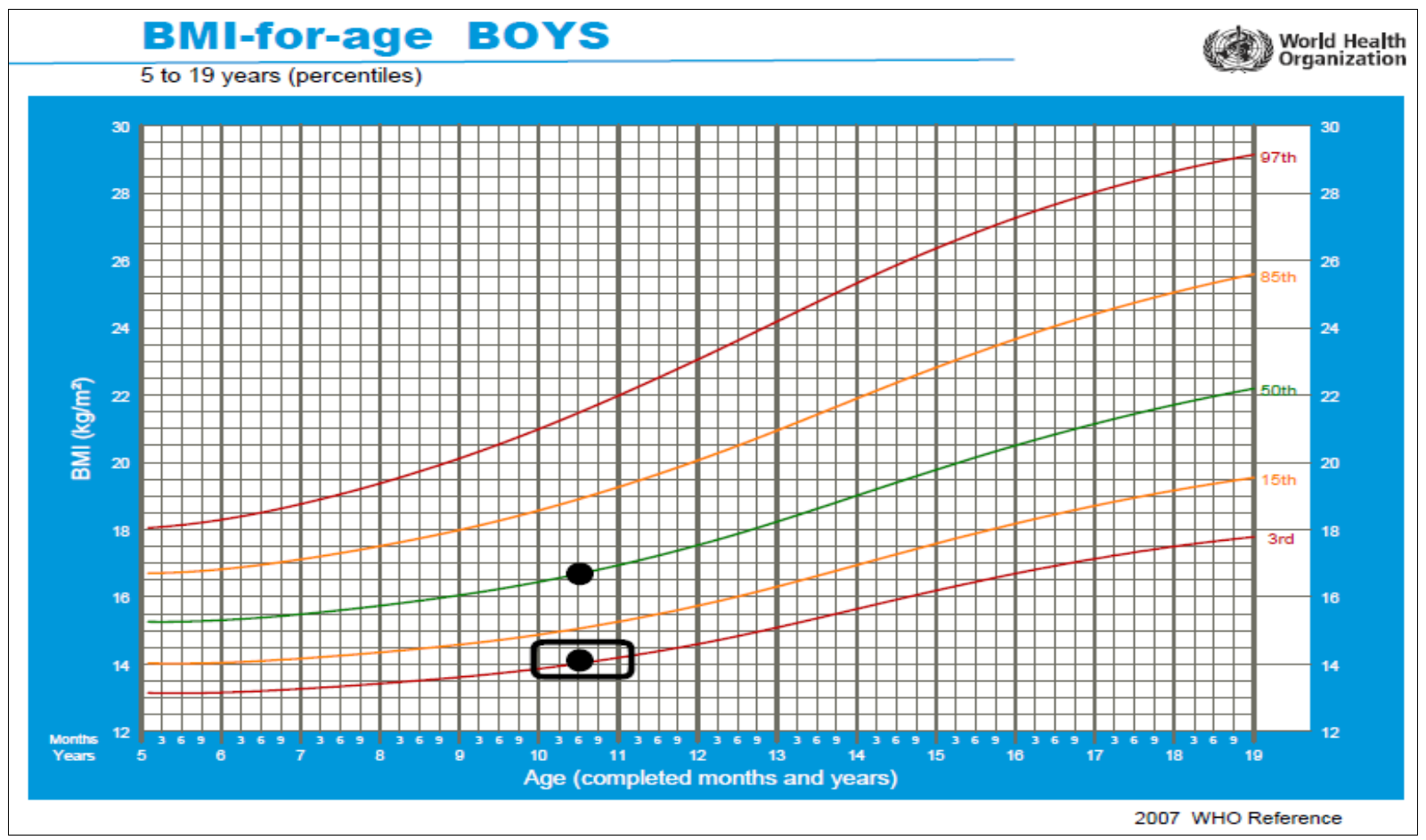

In conclusion, from the present study it was observed that tribal children of Sabarkantha were having lower socio-economic background. Tribal children were living in large families which had number of children. Tribal children were living in kachcha houses and their monthly family income was very low. Mean BMI for age of the tribal children was found lower as compared to ICMR standards. As per Waterlow's classification, stunting, wasting and stunting and wasting was observed and it was found prevalent among tribal children. It was observed that the income of the family showed significant positive correlation with the BMI of the tribal children.

\section{References}

Aggarwal O. P., Bhasin S. K., Sharma A. K., Chhabra P., Aggarwal K., Rajoura O. P. (2005) Ind. J. Commu. Medi., 30(4).

Amerithaveni, M. and C. W. Barikor, 2002. Nutritional status of Meghalayan pre- school children. The Ind. J. Nutr. Diet., 32: 262 .

Anonymous (1986). Use and interpretation of anthropometric indicators of nutritional status. WHO, Working Group. Bulletin of World Health Organization. 1986; 64: 929-41.

Anonymous, 2004. Indian Ministry of Tribal Affairs. The National Tribal Policy (draft), New Delhi, India Ministry of Tribal Affairs.

Anonymous, 2007. World Health Organization (WHO). Child Growth Standards. Geneva: WHO.

Anonymous, 2009. Ministry of Panchayati Raj (September 8, 2009). A Note on the Backward Regions Grant Fund Programme" (PDF). National Institute of Rural Development.

Anonymous, 2009. National Nutrition Monitoring Bureau. Diet and Nutritional Status of Tribal Population and Prevalence of Hypertension among Adults, NNMB Technical Report No. 
25, Report on Second Repeat Survey National Institute of Nutrition Indian Council of Medical Research Hyderabad, India.

Anonymous.

https://www.unicef.org/progressforchild ren/2007n6/index_41505.htm

Anonymous.

https://www.who.int/nutgrowthdb/about /introduction/en/index $2 . \mathrm{html}$

Balgir R.S. (2011). Health scenario of major tribals of northern Orissa in relation to human growth, development and nutrition and the role of genetic factors in smell and tasting abilities in children Online J. Health Allied Sc., 9 (4), 275289.

Bisai S. (2010). Nutrition status based on mid upper arm circumference among urban, poor pre-school children in north 24 parganas, West Bengal, India. Serbian J. Exp.. Clinic. Res., 11(4), 141-145.

Das S. and Bose K., (2011). Assessment of nutritional status by anthropometric indices in Santal tribal children J. Life Sc., 3(2), 81-85.

Dave P. H. and Mistry J.J. (2017). Estimation of health status of tribal farm women of Sabarkantha district. GAU Res. J. 42(1), 21-25.

Dave P. H., Mistry J. J., Chaudhary M. K., (2016). Assessment of nutritional status of tribal school going children of Sabarkantha district, Gujarat. Int. J. Agri. Sci., 8(51), 2308-2311.
Gorstein J., Sullivan K., Yip R de Onís, M., Trowbridge F., Fajans P. and Clugston G. (1994). Bulletin of World Health Organization, 72(2), 273-283.

Laxmaiah A, Rao KM, Hari K R, Arlappa N, Venkaiah K, Brahmam GNV., (2007). Diet and nutritional status of tribal population in ITDA project areas of Khammam district, Andhra Pradesh. $J$. Hum. Ecol. 21(2): 79-86.

Mitra M., Kumar P.V., Chakrabarty S., Bharati P. (2007). Nutritional status of Kamar tribal children in Chhattisgarh. Ind. J. Pedia., 74, 381-384.

Nagtilak S. and Motta T. K. (2014), Nutritional deficiency disorders among tribal school children, DHR Int. J. Medi. Sc., Vol. 5(3): 99-104.

Seksaria S.A. and Sheth M.K. (2013) Paripex - Ind. J. of Res., 2(12), 97:99.

Sonowal C. J., (2010). Factors affecting the nutritional health of tribal children in Maharashtra, Ethno Med, 4(1): 21-36.

Sreedhar T., Prasad U., Bhagya Lakshmi A., Chowdary B., Venugopal P., Kasibabu A., (2016). Study of anaemia in tribal children-a prospective study, IOSR $J$. Dental Medi. Sc. 15(5) 01-05.

Vasudevachary A.K. (2006). Tribal development in Andhra Pradesh. Kurukshetra. J. Rural Dev., 54, 33- 36.

Waterlow J.C., (1972). Classification and definition of protein-calorie malnutrition. British Medi. J., 3, 566569.

\section{How to cite this article:}

Preeti H. Dave, J.J. Mistry, M.K. Chaudhary and Shamal S. Patel. 2019. Prevalence of Malnutrition amongst Tribal School Children of Sabarkantha District, Gujarat, India. Int.J.Curr.Microbiol.App.Sci. 8(03): 2231-2238. doi: https://doi.org/10.20546/ijcmas.2019.803.266 